\title{
Analysis of Heterozygous BRCA1 5382ins Founder Mutation in a Cohort of Egyptian Breast Cancer Female Patients Using Pyrosequencing Technique
}

\author{
Salwa H Gomaa Mogahed ${ }^{1 *}$, Yasser S Hamed², Yassmin E Ibrahim Moursy ${ }^{3}$, \\ Marwa H Mahomoud Saied ${ }^{4}$
}

\begin{abstract}
Background: Up to half of the heritable mutations in breast cancer (BC) are attributed to BRCA1 and BRCA2 genes. The mutation prevalence is variable based on ethnicity and may be influenced by founder mutations. The aim of this pilot study is to determine for the first time, the prevalence of BRCA1 5382insC founder mutation in a cohort of Egyptian familial breast cancer patients (FBC). Methods: Female patients were selected to have familial type of breast cancer. Twenty healthy females were included as a control group. Peripheral blood samples were withdrawn from all studied females and were analyzed for BRCA1 5382insC founder mutation detection using pyrosequencing technique. Results: Eighty Egyptian FBC females were eligible to be enrolled in the study with a mean age of $48.31 \pm$ 10.97 years. We found a BRCA1 5382insC mutation carrier frequency of $5 \%$ of total studied FBC patients (4 out of 80 patients) with $95 \%$ confidence interval (1.61-12.99). There was a high statistical significant difference between carriers and non-carriers concerning the number of affected family members by $\mathrm{BC},(\mathrm{p}=0.001)$. Conclusion: BRCA1 5382insC founder mutation is not uncommon among Egyptian FBC females. The carrier frequency is comparable to that reported worldwide; however it is lower than those from previous Egyptian studies using different molecular techniques. The strong association between the mutation and the number of affected family members suggest wider screening of the mutation among high risk families using the reliable pyrosequencing technique.
\end{abstract}

Keywords: Familial breast cancer- BRCA 1 mutation- Pyrosequencing technique

Asian Pac J Cancer Prev, 21 (2), 431-438

\section{Introduction}

Breast cancer $(\mathrm{BC})$ is the most frequently occurring cancer among women, representing a quarter of all diagnosed cancers (Bray et al., 2018). It is also the first cause of cancer-related deaths among them(DeSantis et al., 2015). In Egypt, according to the latest National Cancer Registry Program (NCRP), BC is the most common cancer among women representing $32.04 \%$ of total cancers (Ibrahim et al., 2014).

$B R C A 1$ and BRCA2 (breast cancer predisposition gene $1 / 2$ )are the strongest susceptibility genes for BCaccounting for up to half of the heritable mutations in $\mathrm{BC}$ and inherited in an autosomal dominant pattern with incomplete penetrance (Tung et al., 2015).

Defective DNA double-strand repair is a characteristic of germline mutations in $B R C A 1$ and $B R C A 2$ genes in all cells expressing them (Mehrgou and Akouchekian, 2016). They are also classified as pathogenic variants or deleterious mutations that predispose to familial breast and or ovarian cancer (Felix et al., 2018; McCartan and Chatterjee, 2018).

These mutations vary among different populations as a result of founder effect (a mutation that occurs more frequently in a particular population) (Ossa and Torres, 2016). BRCA1 5382insC is one of the BRCAlfounder mutations that was linked to Ashkenazi Jewish (Lieberman and Tomer, 2017) and has been implicated in hereditary and familial BC. It is a frame shift mutation in which there is an insertion of a cytosine nucleotide at the position of 5382 of exon 20 of $B R C A 1$ gene resulting into production of truncated premature nonfunctioning protein (Rebbeck et al., 2015).

According to Middle East Cancer Consortium(MECC), the young age at onset as well as high-grade tumor in Middle East and North Africa (MENA) suggest contribution of genetic factors such as BRCAlmutations (Chouchane et al., 2013; Laraqui et al., 2015). A large

${ }^{1}$ Department of Chemical Pathology, ${ }^{2}$ Department of Experimental and Clinical Surgery, Medical Research Institute, ${ }^{3}$ M.B.B.Ch, ${ }^{4}$ Department of Chemical and Clinical Pathology, Faculty of Medicine, Alexandria University, Egypt. *For Correspondence: salwa.hamdi74@yahoo.com 
number of families and frequent consanguinity in the Arab population support the presence of founder mutations (Chouchane et al., 2013). Mutation Data from Egyptian families also suggest the presence of strong $B R C A 1$ and 2 founder effect in their population (Ibrahim et al., 2010).

Given the high penetrance rates among BRCA mutation carriers (depending on their frequency and level of risk), it will be certainly important to identify those who could benefit from the available preventive options such as bilateral prophylactic mastectomy in healthy carriers(Song et al., 2018) as well as those affected women who are indicated for the newly developed gene specific therapies in the era of personalized cancer treatment(Odle, 2017).

Although different molecular techniques have been described for BRCA mutation detection,DNA sequencing is definitely being considered the gold standard as it assisted in analysis of genes at single nucleotide level (Takano et al., 2008).

Pyrosequencing is a real-time sequencing method based on sequence by synthesis (SBS) principle with high throughput in the production of a short length of reads making it a reliable and excellent method for BRCA1 founder mutation detection (Zhang et al., 2009).

Therefore, this study aimed at analysis of BRCA1 5382insC founder mutation in a cohort of Egyptian female population with familial $\mathrm{BC}$ and for the first time by pyrosequencing technique in order to obtain a reliable estimate for its frequency among them.

\section{Materials and Methods}

Egyptian female patients diagnosed with familial breast cancer (FBC), with a family history of $\mathrm{BC}$ in one or more of their first-degree relatives were consecutively enrolled in the study. They were recruited from the Clinical Surgery or medical oncology clinics of Medical Research Institute (MRI), Alexandria University. Twenty age matched healthy females, visiting the breast clinic for routine mammography and with negative family history of $\mathrm{BC}$, were also included as a control group. Written informed consents were taken from all studied subjects. The study was approved by the Ethical Committee of the MRI, Alexandria University. Data were collected from patients' medical records including histopathology of the tumor, cancer stage, presence of metastasis, mammography and fine needle aspiration cytology results as well as hormone receptors and HER2 status. Finally, detection of BRCA1 5382insC mutation in peripheral blood samples from all studied females was done using a pyrosequencing technique.

\section{Pyrosequencing steps}

DNA extraction

DNA was extracted from peripheral blood specimens with Thermo Scientific Gene JET Whole Blood Genomic DNA Purification Mini Kit (Catalog No. K0781) following the manufacturer's protocol. Then the concentration and quality of the purified genomic DNA were assessed by thermoscientificNanoDropTM1000 spectrophotometer.
PCR amplification and visualization of the target DNA

A PyroMark PCR Kit from QIAGEN (Catalog No. 978703) was selected since it enables highly specific and unbiased amplification of template DNA. For each PCR reaction the following were added: $12.5 \mu \mathrm{l}$ of PyroMark PCR MasterMix, $3 \mu \mathrm{l}$ Primer (100 $\mu \mathrm{mol}), 2.5 \mu 1$ CoralLoadConcentrate, $4.5 \mu \mathrm{l}$ RNase-Free Water and $2.5 \mu \mathrm{l}$ Template DNA to reach a final volume of $25 \mu \mathrm{l}$. We used two oligonucleotide primers (forward and reverse) (Zhang et al., 2009) that flank the mutation locus:BRCA1 5382insC forward: 5'-AAAGCGAGCAAGAGAATCCC-3'and BRCA1 5382insC reverse:5'-TGGGGTGAGATTTTTGTCAAC3'-biotin.(One of the primers must be biotin-labeled to enable binding of the PCR product to streptavidin-coated beads during the preparation of single-stranded Pyrosequencing template), Table (1). PCR was performed using PCR Machine (Arktik Thermal Cycler, Thermo Scientific, USA).The PCR conditions were optimized and programmed as shown in Table 2. Then, all PCR amplicons were checked over $2 \%$ agarose gel electrophoresis to ensure the presence of a single clear band (without secondary product or primer dimer) before pyrosequencing, Figure 1.

\section{Pyrosequencing detection of heterozygous BRCA1} 5382ins C mutation

Using QiagenPyroMark Q24 Gold kit (Catalog No. 970802), the PCR products were analyzed for BRCA1 5382insC mutation by sequencing on a PyroMark Q24 following the manufacturer's instructions using the pyrosequencing primer: 5'-CGAGCAAGAGAATCCC-3', Table 1. Sequences to be analyzed and nucleotide dispensation order are shown in Figure 2 under each pyrogram.

\section{Design of the pyrosequencing assay}

The assay was designed to start sequence analysis right at the mutation site (BRCA1 5382insC). Then, the PyroMark Q24 was programmed with the protocol of sequential nucleotide dispensation. Besides, negative nucleotide dispensations were inserted to serve as internal controls to avoid nucleotide misincorporation. Peak heights are proportional to the nucleotides' numbers that are incorporated with each dispensation.

Analyzing the data by PyroMark Q24 Software and obtaining the results

PyroMark Q24 Software, installed on a personal computer, enables analysis of the results in the form of pyrogram for each sample.

\section{Statistical Analysis}

Statistical analysis was done using SPSS program version 20 (Statistical Package of Social Sciences, Chicago, USA). The distributions of quantitative variables were tested for normality using Kolmogorov-Smirnov test. Normally distributed test results were represented in the form of Mean \pm Standard deviation. Independent samples t-test was used to compare quantitative variables between 2 groups. The data of the nominal variables were 
Table 1. The PCR Primers and Sequencing Primer Used for BRCA1 5382insc Founder Mutation Analysis by Pyrosequencing

\begin{tabular}{llll}
\hline Mutation & \multicolumn{1}{c}{ Primer name } & \multicolumn{1}{c}{ Primer sequence* } & Product size(bp) \\
\hline \multirow{2}{*}{ BRCA1 5382insC } & 5382insC-F & 5382insC (biotinylated) & 5'-TGGGGCGAGCAAGAGAATCCC-3' \\
& Sequencing primer & 5'-CGAGCAAGAGAATCCC-3' & 72 \\
\hline
\end{tabular}

*The GenBank references for primer sequences are: BRCA1 (NM 007304)

Table 2. PCR Cycling Protocol

\begin{tabular}{lc}
\hline \multicolumn{2}{c}{ Optimized cycling protocol } \\
\hline Initial PCR activation step & $15 \mathrm{~min}$ at $94^{\circ} \mathrm{C}$ \\
3-step cycling: Denaturation & $30 \mathrm{sec}$ at $94^{\circ} \mathrm{C}$ \\
Annealing & $30 \mathrm{sec}$ at $55^{\circ} \mathrm{C}$ \\
Extension & $30 \mathrm{sec}$ at $72^{\circ} \mathrm{C}$ \\
Number of cycles & $45 \mathrm{cycle}$ \\
Final extension & $10 \mathrm{~min}$ at $72^{\circ} \mathrm{C}$ \\
\hline
\end{tabular}

summarized in the form of frequencies and percentages. The Chi-Square test ( $\chi^{2}$ test) was used to compare proportions of $B R C A 1$ carriers and non-carriers according to nominal clinical data variables. When more than $20 \%$ of the cells have expected count less than 5, correction for chi-square was conducted using Fisher's Exact test or Monte Carlo correction. Significance of the obtained results was judged by $\mathrm{p}$ - value $<0.05$ (Daly and Bourke, 2008).

\section{Results}

Between 2017 and 2018, a total of 80 eligible FBC females were included in the study together with the 20 healthy volunteers. All demographic and clinical data as regards age of presentation, all reproductive factors as well as tumor stage and immunohistochemistry examination of the breast tumor tissues (hormone receptor profile and molecular subtypes of BC) are shown in Table 3.

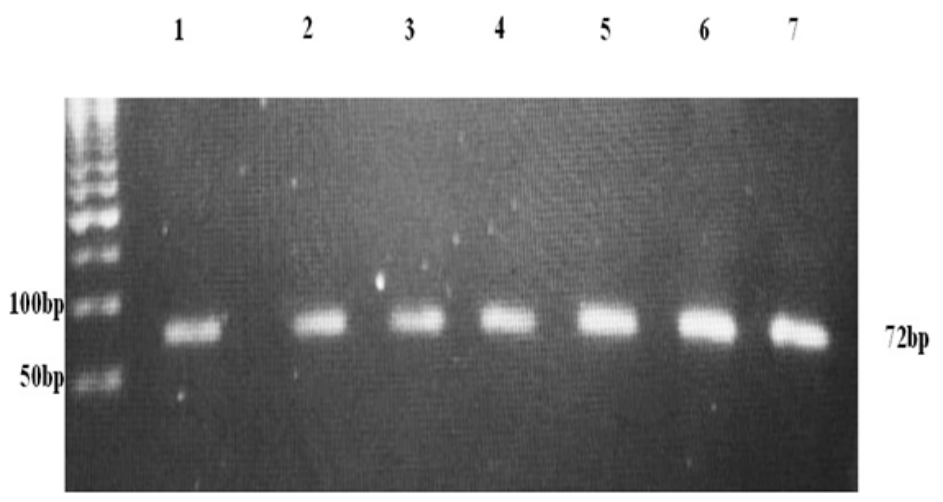

Figure 1. Visualization of PCR Products on Gel Prior to Pyrosequencing. 50 bp Ladder (on the Left) and the Product Band at 72 bp for Seven Different Samples (on the Right).

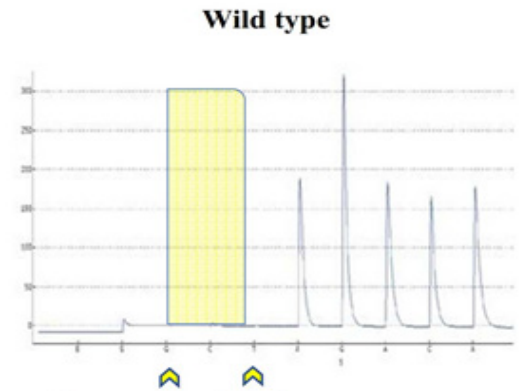

Sequence analysed:

$\begin{array}{ll}\text { Wt allele } & \text { A } \text { GG A C A } \\ \text { Wt allele } & \text { A }\end{array}$

Figure (2-a): Pyrogram 1

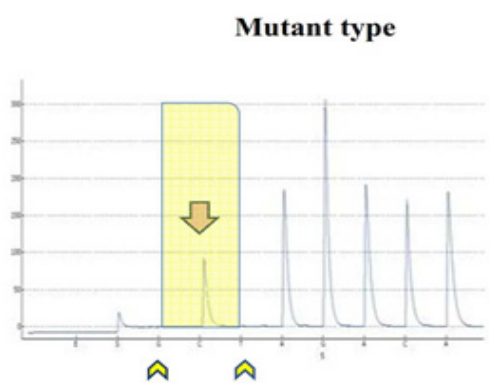

Sequence analysed:
Wt allele
A GG A C A
Mut allele
(C) A GG A C A

Figure (2-b): Pyrogram 2

Figure 2. Pyrograms Showing Heterozygous Insertion of $\mathrm{C}$ Indicated by an Arrow that is Present in the Mutant (2-b), but not in the Wild-Type (2-a) of BRCA1 5382insC. Pyrograms at positions 1 and 3 shows one unit $\mathrm{G}$ and one unit $\mathrm{T}$ (arrowheads) which are negative nucleotide dispensations that serve as internal controls for nucleotide misincorporation. 
Table 3. Distribution of the Studied Familial Breast Cancer Patients According to Demographic and Clinical Parameters $(\mathrm{N}=80)$

\begin{tabular}{lcc}
\hline & No. & $\%$ \\
\hline Age of first presentation (years) & 48.31 & 10.97 \\
$\leq 50$ & 44 & 55.00 \\
$>50$ & 36 & 45.00 \\
No. of affected family members & & \\
One relative & 57 & 71.25 \\
Two relatives & 14 & 17.50 \\
Three relatives & 9 & 11.25
\end{tabular}

Different types of cancers in the relatives of FBC patients

\begin{tabular}{|c|c|c|}
\hline Breast & 101 & 90.18 \\
\hline Others & 11 & 9.82 \\
\hline \multicolumn{3}{|l|}{ Menstrual history } \\
\hline Premenopausal & 46 & 57.50 \\
\hline Menopausal & 34 & 42.50 \\
\hline \multicolumn{3}{|l|}{ Marital status } \\
\hline Not married & 10 & 12.50 \\
\hline Married & 70 & 87.50 \\
\hline \multicolumn{3}{|l|}{ Parity } \\
\hline Nulliparous & 11 & 13.75 \\
\hline Multiparous & 69 & 86.25 \\
\hline Breast feeding & 69 & 86.25 \\
\hline \multicolumn{3}{|l|}{ Clinical presentation } \\
\hline Breast lump & 70 & 86.42 \\
\hline Others & 11 & 13.58 \\
\hline \multicolumn{3}{|l|}{ Mammography } \\
\hline BIRADS IV & 35 & 43.75 \\
\hline BIRADS V & 35 & 43.75 \\
\hline Others & 10 & 12.50 \\
\hline \multicolumn{3}{|l|}{ Histopathological type } \\
\hline IDC & 67 & 83.75 \\
\hline Others(ILC,DCIS and mixed mucinous) & 13 & 16.25 \\
\hline \multicolumn{3}{|l|}{ TNM Stage } \\
\hline II & 37 & 46.25 \\
\hline III & 22 & 27.50 \\
\hline IV & 11 & 13.75 \\
\hline Others (stage 0 and I) & 10 & 12.50 \\
\hline Non-metastasis & 69 & 86.25 \\
\hline Metastasis & 11 & 13.75 \\
\hline \multicolumn{3}{|l|}{ Hormone receptor and HER2 status } \\
\hline ER+ PR+ HER2-ve (Luminal A) & 51 & 63.75 \\
\hline ER+ PR+ HER2+ve (Triple positive) & 10 & 12.50 \\
\hline HER2+ve (HER2 enriched) & 10 & 12.50 \\
\hline ER- PR- HER2-ve (Triple negative) & 9 & 11.25 \\
\hline \multicolumn{3}{|l|}{ Carrier status of BRCA1 5382insC mutation } \\
\hline Non-carrier & 76 & 95 \\
\hline Carrier & 4 & 5 \\
\hline
\end{tabular}

IDC, Infiltrating ductal carcinoma; ILC, Invasive lobular carcinoma; DCIS, Ductal carcinoma in situ

\section{Interpretation of the pyrograms}

Following pyrosequencing analysis of samples, pyrograms were extracted and interpreted. As shown in Figure 2, incorporation of an extra nucleotide $\mathrm{C}$, in case of BRCA1 5382insC mutation, was seen in the mutant allele, Figure (2-b) which is absent in the wild type, Figure 2-a, (a very clear distinct pyrogram). As the peak intensity of the $\mathrm{C}$ (one light unit) is approximately half of other peaks at positions $4,6,7,8$, it represents insertion of $\mathrm{C}$ in only one of the alleles (heterozygous insC). All mutant genotypes were confirmed by repeat analysis.

\section{BRCA1 5382ins C mutation carriers and non-carriers}

As regards BRCA1 5382insC heterozygous mutation, the present study found a carrier frequency of $5 \%$ of total studied FBC Egyptian patients (4 out of 80 patients) with $95 \%$ confidence interval (1.61-12.99). Most of patients had (Luminal A) molecular subtype as (63.2\% among noncarriers) and (75\% among carriers). Detailed description and clinical characteristics of each carrier are shown in Table (4). Notably, none of the healthy females $(0 / 20$, $0 \%$ ) had the BRCA1 5382insC heterozygous mutation.

Association of BRCA mutation carrier status and the clinical parameters

Therefore, according to the carrier status, the studied FBC patients were further divided into two subgroups (carriers and non-carriers) to investigate possible associations of BRCA1 5382insC mutation with clinical representations of patients, Table 5 .

\section{Discussion}

Data related to familial and hereditary BC among the Arab population are rare with few reported from Egypt, however they support the presence of BRCA founder mutation in this population.(Ibrahim et al., 2010; Chouchane et al., 2013).

$B R C A 1$ 5382insC, is the second most recurrent mutation reported in the BRCAl gene in different countries, according to the breast cancer information core (BIC) (Odle, 2017).

The present study reported for the first time the prevalence of $B R C A 15382$ ins $C$ founder mutation among Egyptian FBC patients using pyrosequencing technique. The heterozygous mutation was detected in 4 out of 80 patients with a carrier frequency of 5\% (95\% confidence interval 1.61-12.99), Table 3. Worldwide population studies have revealed comparable mutation frequency in different countries; as in Ashkenazi Jewish (6\% early onset BC), Dagan et al., (2017) in Greek (5.5\% in breast /ovarian cancer families), Konstantopoulou et al., (2014) in South Africa (3.3\% in breast and /or ovarian cancer families) Reeves et al., (2004) and other populations worldwide (Backe et al., 1999; Jasinska and Krzyzosiak, 2001; Sokolenko et al., 2006; Fernandes et al., 2016).

To date, no published data from Egypt about BRCA1 5382 ins $C$ prevalence using pyrosequencing. After serious search, we found only one Egyptian study that determined another BRCA1 (185delAG) founder mutation using pyrosequencing technique and reported a carrier 
DOI:10.31557/APJCP.2020.21.2.431

BRCA1 5382insC Founder Mutation Detection by Pyrosequencing

Table 4. Clinical Description of BRCA1 5382insC Mutation Carriers

\begin{tabular}{lcccc}
\hline & Carrier 1 & Carrier 2 & Carrier 3 & Carrier 4 \\
\hline Age of first presentation (years) & 40 & 32 & 48 & 41 \\
Menopausal state & Premenopause & Premenopause & Premenopause & Premenopause \\
& Sister BC & Sister BC died & MotherBC died & Mother BC \\
Family history & Father brain & Aunt BC died & Aunt bilateral BC & Aunt BC \\
& Brother lung & Uncle GIT & & Sister BC \\
Mammography & BIRADS IV & BIRADS V & BIRADS IV & BIRADS V \\
Pathology & IDC & IDC & IDC & IDC \\
Cancer stage & III & III & II & IV \\
Visceral metastasis & Free & Free & Free & Free \\
Bone metastasis & Free & Free & Free & Positive \\
Hormone receptors and HER2 status & ER, PR -ve & ER, PR +ve & ER, PR +ve & ER, PR +ve \\
& HER2 +ve & HER2 -ve & HER2 -ve & HER2 -ve \\
HER2 enriched & Luminal A & Luminal A & Luminal A \\
BIRADS, Breast Imaging; Reporting and Data System IDC, Infiltrating ductal carcinoma; ILC, Invasive lobular carcinoma; DCIS, Ductal carcinoma \\
in situ; ER, Estrogen receptors; PR, Progesterone receptors; HER2, The human epidermal growth factor receptor 2; BRCA1, Breast cancer gene 1
\end{tabular}

Table 5. Comparison between Mutation Carrier and NonCarrier Cases according to Their Clinical Parameters

\begin{tabular}{|c|c|c|c|c|c|}
\hline & \multicolumn{2}{|c|}{$\begin{array}{l}\text { Non-carrier } \\
(\mathrm{n}=76)\end{array}$} & \multicolumn{2}{|c|}{$\begin{array}{l}\text { Carrier } \\
(\mathrm{n}=4)\end{array}$} & \multirow[t]{2}{*}{ FEp } \\
\hline & No. & $\%$ & No. & $\%$ & \\
\hline $\begin{array}{l}\text { Age of first presentation } \\
\text { (years) }\end{array}$ & $48.74 \pm$ & 11.01 & $40.25 \pm$ & 6.55 & 0.132 \\
\hline$\leq 50$ & 40 & 52.6 & 4 & 100 & 0.123 \\
\hline$>50$ & 36 & 47.4 & 0 & 0 & \\
\hline \multicolumn{6}{|l|}{ Menstrual history } \\
\hline Premenopausal & 42 & 55.3 & 4 & 100 & 0.133 \\
\hline Menopausal & 34 & 44.7 & 0 & 0 & \\
\hline \multicolumn{6}{|l|}{ Marital status } \\
\hline Not married & 8 & 10.5 & 2 & 50 & 0.074 \\
\hline Married & 68 & 89.5 & 2 & 50 & \\
\hline \multicolumn{6}{|l|}{ Parity } \\
\hline Nulliparous & 9 & 11.8 & 2 & 50 & 0.089 \\
\hline Multiparous & 67 & 88.2 & 2 & 50 & \\
\hline \multicolumn{6}{|l|}{ Breast feeding } \\
\hline Negative & 9 & 11.8 & 2 & 50 & 0.089 \\
\hline Positive & 67 & 88.2 & 2 & 50 & \\
\hline \multicolumn{6}{|l|}{ Mammography } \\
\hline BIRADS I & 1 & 1.32 & 0 & 0 & 1 \\
\hline BIRADS II & 1 & 1.32 & 0 & 0 & \\
\hline BIRADS III & 6 & 7.89 & 0 & 0 & \\
\hline BIRADS IV & 33 & 43.42 & 2 & 50 & \\
\hline BIRADS V & 33 & 43.42 & 2 & 50 & \\
\hline BIRADS VI & 2 & 2.63 & 0 & 0 & \\
\hline \multicolumn{6}{|l|}{ Histopathological type } \\
\hline IDC & 63 & 82.9 & 4 & 100 & 1 \\
\hline ILC & 9 & 11.84 & 0 & 0 & \\
\hline DCIS & 2 & 2.63 & 0 & 0 & \\
\hline $\begin{array}{l}\text { Mixed mucinous } \\
\text { carcinoma }\end{array}$ & 2 & 2.63 & 0 & 0 & \\
\hline
\end{tabular}

Table 5. Continued

\begin{tabular}{|c|c|c|c|c|c|}
\hline & \multicolumn{2}{|c|}{$\begin{array}{l}\text { Non-carrier } \\
(\mathrm{n}=76)\end{array}$} & \multicolumn{2}{|c|}{$\begin{array}{l}\text { Carrier } \\
(\mathrm{n}=4)\end{array}$} & \multirow[t]{2}{*}{$\mathrm{FE}_{\mathrm{p}}$} \\
\hline & No. & $\%$ & No. & $\%$ & \\
\hline \multicolumn{6}{|l|}{ TNM Stage } \\
\hline 0 & 2 & 2.6 & 0 & 0 & 0.619 \\
\hline I & 8 & 10.5 & 0 & 0 & \\
\hline II & 36 & 47.4 & 1 & 25 & \\
\hline III & 20 & 26.3 & 2 & 50 & \\
\hline IV & 10 & 13.2 & 1 & 25 & \\
\hline \multicolumn{6}{|l|}{ Metastasis } \\
\hline Negative & 66 & 86.8 & 3 & 75 & 0.453 \\
\hline Positive & 10 & 13.2 & 1 & 25 & \\
\hline $\begin{array}{l}\text { ER+ PR+ HER2- } \\
\text { ve(Luminal A) }\end{array}$ & 48 & 63.2 & 3 & 75 & 1 \\
\hline $\begin{array}{l}\text { ER }+ \text { PR }+ \\
\text { HER2+ve(Triple +ve })\end{array}$ & 10 & 13.2 & 0 & 0 & 1 \\
\hline $\begin{array}{l}\text { ER-PR-HER2+ve } \\
\text { (HER2 enriched) }\end{array}$ & 9 & 11.8 & 1 & 25 & 0.42 \\
\hline $\begin{array}{l}\text { ER- PR- HER2- } \\
\text { ve(Triple negative) }\end{array}$ & 9 & 11.8 & 0 & 0 & 1 \\
\hline \multicolumn{6}{|l|}{ Family history } \\
\hline One relative & 57 & 75.0 & 0 & 0 & $0.001 *$ \\
\hline Two relatives & 13 & 17.1 & 1 & 25 & \\
\hline Three relatives & 6 & 7.9 & 3 & 75 & \\
\hline \multicolumn{6}{|l|}{1 year Survivability } \\
\hline Unknown & 3 & 3.9 & 0 & 0 & 1 \\
\hline Died & 5 & 6.6 & 0 & 0 & \\
\hline Survived & 68 & 89.5 & 4 & 100 & \\
\hline
\end{tabular}

p, p-value for comparing between the two groups; *, Statistically significant at $\mathrm{p} \leq 0.05 ; \mathrm{FE}$, Fisher exact test

frequency of $2.5 \%$ among the studied BC females (Saied et al., 2017).

Some studies from Egypt discussed BRCA1 and or $B R C A 2$ mutations using other techniques. For example, 
a previous work by (Abdel-Mohsen et al., 2016) revealed the presence of $B R C A 15382$ insC in $66.7 \%$ of $\mathrm{BC}$ patients compared with $10 \%$ among healthy controls using methylation specific-PCR and PCR-RFLP.

On the contrary, a very recent study by (Abou-El-Naga et al., 2018) found a higher frequency of $B R C A 15382 \mathrm{ins} C$ among BC patients $(11.6 \%)$ relative to $B R C A 1185 \mathrm{delAg}$ $(2.3 \%)$ but they also found a higher frequency of $B R C A 1$ 5382insC mutation among unrelated controls (49.5\%) and first-degree relatives of mutation carriers $(6.3 \%)$, using multiplex-PCR technique.

The variability of our results from those of other studies may be attributed to difference in methodology of testing, criteria used for patient selection and number of studied populations as well. As regards the methodology, those based on digestion approach are suspected to have lower performance as the other mutations that could be present in the targeted $B R C A 1$ gene isolates could alter the restriction enzyme recognition sites causing false-negative or false-positive results. In addition, compared to Sanger sequencing, pyrosequencing is cost effective and ideal for short fragments sequencing (Fuller et al., 2016).

In the current study, the mean age of studied FBC patients was 48.31 years old, Table 3 . The mean age of first presentation in BRCA1 5382insC mutation carriers (40.25 years) was lower than that of non-carriers (48.74 years) with no statistically significant difference, Table (5). This was in concordance with a very recent research by Kwong et al., (2018) who found younger age at presentation (42.36 years) in BRCA mutations than that of the studied high risk group (47.11 years). Similar finding was reported by Ibrahim et al., (2010) and Cronin-Fenton et al., (2017).

The present study showed that BC was the most prevalent cancer among relatives of carriers and non-carriers as it represents $90.18 \%$ of all cancers among them, Table 3. BRCA1 5382insC carriers had relatives with $\mathrm{BC}$, bilateral BC, GIT, lung and brain tumors, Table 4 . Ozsoy et al., (2017) suggested that family history of BC is the most important risk factor among all other risk factors. Similarly, other studies such as(Jasinska and Krzyzosiak, 2001; Cherbal et al., 2010) found a strong family history of $\mathrm{BC}$ in all carriers of BRCA1 5382insC mutation.

In the present study 3 out of $4(75 \%)$ of the carrier group had 3 family members affected with cancers, Table 5. In line with our study, Pajares et al., (2018) reported that among the studied BRCA1-mutated families, the most frequent criterion was the presence of three or more family members with breast and/or ovarian cancer.

Interestingly, the present study revealed for $B R C A 1$ 5382 insC carrier number (1), that the affected first degree relatives were from the father side, since father, brother and sister of the same patient had cancers (brain, lung and breast cancers respectively), Table 4. Aggregation of such tumors with $\mathrm{BC}$ in the same family draw the attention to family cancer syndrome with various cancers among family which most probably due to a tumor suppressor gene mutation. Therefore, for all carriers identified, a complete screening for coding regions of BRCA genes is necessary. Notably, it had been reported that TP53 mutations were found in concomitant with BRCA1 associated breast tumors Crook et al., (1997). Consequently, targeted deep sequencing of common variants in both BRCA and TP53 genes in those carriers is essential.

Concerning the hormone receptor and HER2 status (ER, PR, and HER2), our study showed no statistical significant difference between carrier and non-carrier groups. Only an increased incidence of ER+ PR+ BC among studied FBC patients was identified, Table 5. Molino et al., (2004) reported that BC patients with a positive family history were more likely to have ER+ tumors with no significant association between PR+ tumors and family history. Remarkably, in the present study, triple negative $\mathrm{BC}$ was found in only $11.25 \%$ of FBC patients (9/80), Table 3 and none was a carrier for BRCA1 5382insC mutation, Table 5.

On contrary, other studies found that triple negative $\mathrm{BC}$ was more common in BRCA mutations carriers, while triple positive tumors were more common in non-carriers. (Alemar et al., 2017; Chen et al., 2018). Furthermore, HER2-positive phenotype is a molecular subtype not frequently associated with BRCA deficiency (Maynes et al., 2010). Interestingly, carrier number (1) in our study had HER2 enriched phenotype, Table (4), and showed a good response to targeted chemotherapy i.e. Herceptin.

Moreover, in the current study, there were no statistical significance differences as regards Tumor stage, distant metastasis and one year survivability between carrier and non-carrier groups, Table 5.

The association between BRCA mutations and survivability is controversial as $\mathrm{BC}$ prognosis in BRCA mutation carriers remains poorly understood. In line with current study, Yadav et al., (2018) found no statistical significant difference in overall survival (OS) between the BRCA mutation carriers and non-carriers. Conversly, (van den Broek et al., 2015) were found to be heterogenous and indecisive. Also, Schmidt et al., (2017) concluded a worse prognosis among $B R C A 1$ or $B R C A 2$ mutation carriers diagnosed with $\mathrm{BC}$ before age of 50 years. They explained their findngs by difference in tumor characteristics, treatment response and second ovarian cancers.

We conclude from our study that BRCA1 5382insC founder mutation was detected in the studied Egyptian familial breast cancer (FBC) female patients with 5\% carrier frequency that was comparable to worldwide frequencies, but lower than those reported from earlier Egyptian studies. BRCA1 5382insC mutation carriers are younger than non-carriers at their first presentation. Moreover, a strong association was found between occurrence of BRCA1 5382insC mutation and the number of affected family members by BC. Therefore, we suggest wider screening of the mutation among high risk families in Egypt using pyrosequencing technique that could be an excellent platform for BRCA founder mutation analysis.

\section{Acknowledgments}

We would like to thank all patients and volunteers for their contribution to this work. The study is a part of a thesis approved by local ethics committee of Medical Research Institute, Alexandria University in partial fulfilment of the requirements for the degree of Master of science in Chemical Pathology. The study was not funded 
from any funding organization.

\section{References}

Abdel-Mohsen MA, Ahmed OA, El-Kerm YM (2016). BRCA1 gene mutations and influence of chemotherapy on autophagy and apoptotic mechanisms in Egyptian breast cancer patients. Asian Pac J Cancer Prev, 17, 1285-92.

Abou-El-Naga A, Shaban A, Ghazy H, et al (2018). Frequency of BRCA1 (185delAG and 5382insC) and BRCA2 (6174delT) mutations in Egyptian women with breast cancer compared to healthy controls. Meta Gene, 15, 35-41.

Alemar B, Gregório C, Herzog J, et al (2017). BRCA1 and $B R C A 2$ mutational profile and prevalence in hereditary breast and ovarian cancer (HBOC) probands from Southern Brazil: Are international testing criteria appropriate for this specific population?. PLoS One, 12, e0187630.

Backe J, Hofferbert S, Skawran B, et al (1999). Frequency of BRCA1 mutation 5382insC in German breast cancer patients. Gynecol Oncol, 72, 402-6.

Bray F, Ferlay J, Soerjomataram I, et al (2018). Global cancer statistics 2018: GLOBOCAN estimates of incidence and mortality worldwide for 36 cancers in 185 countries. $C A$ Cancer J Clin, 68, 394-424.

Chen H, Wu J, Zhang Z, et al (2018). Association between BRCA status and triple-negative breast cancer: a meta-analysis. Front Pharmacol, 9, 909.

Cherbal F, Bakour R, Adane S, et al (2010). BRCA1 and BRCA2 germline mutations screening in Algerian breast/ovarian cancer families. Dis Markers, 28, 377-84.

Chouchane L, Boussen H, Sastry KS (2013). Breast cancer in Arab populations: molecular characteristics and disease management implications. Lancet Oncol, 14, 417-24.

Cronin-Fenton DP, Kjaersgaard A, Norgaard M, et al (2017). Clinical outcomes of female breast cancer according to BRCA mutation status. Cancer Epidemiol, 49, 128-37.

Crook T, Crossland S, Crompton MR, et al (1997). p53 mutations in BRCA1-associated familial breast cancer. Lancet, $\mathbf{3 5 0}$, 638-9.

Dagan E, Gershoni-Baruch R, Kurolap A, et al (2017). Early onset breast cancer in Ashkenazi women carriers of founder BRCA 1/2 mutations: beyond 10 years of follow-up. Eur $J$ Cancer Care, 26, e12594.

Daly L, Bourke GJ (2008). Interpretation and Uses of Medical Statistics. John Wiley and Sons, London. 2008.

DeSantis CE, Bray F, Ferlay J, et al (2015). International variation in female breast cancer incidence and mortality rates. Cancer Epidemiol Biomarkers Prev, 24, 1495-506.

Felix GES, Zheng Y, Olopade OI (2018). Mutations in context: implications of BRCA testing in diverse populations. Fam Cancer, 17, 471-83.

Fernandes GC, Michelli RA, Galvão HC, et al (2016). Prevalence of BRCA1/BRCA2 mutations in a Brazilian population sample at-risk for hereditary breast cancer and characterization of its genetic ancestry. Oncotarget, 7, 80465 .

Fuller CW, Kumar S, Porel M, et al (2016). Real-time single-molecule electronic DNA sequencing by synthesis using polymer-tagged nucleotides on a nanopore array. Proc Natl Acad Sci U S A,113, 5233-8.

Ibrahim AS, Khaled HM, Mikhail NN, et al (2014). Cancer incidence in egypt: results of the national population-based cancer registry program. J Cancer Epidemiol, 2014, 437971.

Ibrahim SS, Hafez EE, Hashishe MM (2010). Presymptomatic breast cancer in Egypt: role of BRCA1 and BRCA2 tumor suppressor genes mutations detection. J Exp Clin Cancer Res, 29, 82.

Jasinska A, Krzyzosiak WJ (2001). Prevalence of BRCA1 founder mutations in western Poland. Hum Mut, 17, 75.

Konstantopoulou I, Tsitlaidou M, Fostira F, et al (2014). High prevalence of BRCA1 founder mutations in Greek breast/ ovarian families. Clin Genet, 85, 36-42.

Kwong A, Ho JC, Shin VY, et al (2018). Rapid detection of $B R C A 1 / 2$ recurrent mutations in Chinese breast and ovarian cancer patients with multiplex $\mathrm{SNaPshot} \mathrm{genotyping} \mathrm{panels.}$ Oncotarget, 9, 7832.

Laraqui A, Uhrhammer N, El Rhaffouli H, et al (2015). BRCA genetic screening in Middle Eastern and North African: mutational spectrum and founder BRCA1 mutation (c. 798 799delTT) in North African. Dis Markers, 2015, 1-8.

Maynes D, Hunt K, Pockaj B, et al (2010). Are HER2-positive breast cancer and BRCA mutation-associated breast cancer mutually exclusive diseases? Evidence from the Mayo Clinic Arizona Cohort. J Clin Oncol, 28, e21075-e.

McCartan D, Chatterjee S (2018). Hereditary and familial cancer. Surgery, 36, 145-50.

Mehrgou A, Akouchekian M (2016). The importance of BRCAI and $B R C A 2$ genes mutations in breast cancer development. Med J Islam Repub Iran, 30, 369.

Molino A, Giovannini M, Pedersini R, et al (2004). Correlations between family history and cancer characteristics in 2256 breast cancer patients. Br J Cancer, 91, 96.

Odle TG (2017). Precision medicine in breast cancer. Radiol Technol, 88, 401-21.

Ossa CA, Torres D (2016). Founder and recurrent mutations in $B R C A 1$ and BRCA2 genes in Latin American countries: State of the Art and Literature Review. Oncologist, 21, 832-9.

Ozsoy A, Barca N, Dolek BA, et al (2017). The relationship between breast cancer and risk factors: A single-center study. Eur J Breast Health, 13, 145-9.

Pajares B, Porta J, Porta JM, et al (2018). Hereditary breast and ovarian cancer in Andalusian families: a genetic population study. BMC Cancer, 18, 647.

Rebbeck TR, Mitra N, Wan F, et al (2015). Association of type and location of $B R C A 1$ and $B R C A 2$ mutations with risk of breast and ovarian cancer. JAMA, 313, 1347-61.

Reeves MD, Yawitch TM, van der Merwe NC, et al (2004). BRCA1 mutations in South African breast and/or ovarian cancer families: evidence of a novel founder mutation in Afrikaner families. Int J Cancer, 110, 677-82.

Saied MH, El Boraie S, Elfayoumy T, et al (2017). Detection of BRCA1 founder mutation 185DELAG in breast cancer patients using pyrosequencing technique. Breast Can Curr Res, $2,117$.

Schmidt MK, Van Den Broek AJ, Tollenaar RA, et al (2017). Breast cancer survival of $B R C A 1 / B R C A 2$ mutation carriers in a hospital-based cohort of young women. $J$ Natl Cancer Inst, 109, djw329.

Sokolenko AP, Mitiushkina NV, Buslov KG, et al (2006). High frequency of BRCA1 5382insC mutation in Russian breast cancer patients. Eur J Cancer, 42, 1380-4.

Song C-V, Teo S-H, Taib NA, et al (2018). Surgery for BRCA, TP53 and PALB2: a literature review. Cancer Med Sci, 12, 863.

Takano EA, Mitchell G, Fox SB, et al (2008). Rapid detection of carriers with $B R C A 1$ and $B R C A 2$ mutations using high resolution melting analysis. $B M C$ Cancer, $\mathbf{8}, 59$.

Tung N, Battelli C, Allen B, et al (2015). Frequency of mutations in individuals with breast cancer referred for $B R C A 1$ and $B R C A 2$ testing using next-generation sequencing with a 25-gene panel. Cancer, 121, 25-33.

Van den Broek AJ, Schmidt MK, van't Veer LJ, et al (2015). Worse breast cancer prognosis of BRCA1/BRCA2 mutation carriers: what's the evidence? A systematic review with meta-analysis. PLoS One, 10, e 0120189. 
Salwa H. Gomaa Mogahed et al

Yadav S, Ladkany R, Yadav D, et al (2018). Impact of BRCA mutation status on survival of women with triple-negative breast cancer. Clin Breast Cancer, 18, 1229-35.

Zhang L, Kirchhoff T, Yee CJ, et al (2009). A rapid and reliable test for $B R C A 1$ and $B R C A 2$ founder mutation analysis in paraffin tissue using pyrosequencing. J Mol Diagn, 11, 176-81.

\section{@ $(0 \otimes$}

This work is licensed under a Creative Commons AttributionNon Commercial 4.0 International License. 